\title{
Low back pain in children: a rising concern
}

\author{
Jennifer Hwang ${ }^{1,2} \cdot$ Philip K. Louie ${ }^{1,2} \cdot$ Frank M. Phillips $s^{1,2} \cdot$ Howard S. An $^{1,2} \cdot$ Dino Samartzis $^{1,2}$
}

Received: 23 November 2018 / Accepted: 25 November 2018 / Published online: 30 November 2018

(c) Springer-Verlag GmbH Germany, part of Springer Nature 2018

Pediatric health is a worldwide concern that is often overlooked and under-represented. Various conditions and disorders (e.g., musculoskeletal deformities, congenital/developmental syndromes, mental health, obesity) that arise during childhood may have substantial implications to a child's daily function, social interactions, quality of life, family dynamics, and psychological well-being [1,2]. The diverse effects of these health conditions may remain and become compounded into adulthood. This impact has been shown to have direct implications to health-care costs, imposing a severe socioeconomic burden to society [3-5]. Specifically, one such condition affecting children is low back pain (LBP).

Back pain has previously been, in large part, considered uncommon in children and/or dismissed. As the diagnosis can be overshadowed by episodic pain in adults, characterization of pediatric low back pain has been seldom studied in the population and throughout various ethnic groups. However, as of recent, a global rise in incidence of LBP in adolescents has been noted, albeit with limited studies to support its epidemiology and etiology. In recent years, the prevalence of pediatric LBP has trended upward from $2-11 \%$ to $27-51 \%$ [6-9]. Other reports have noted a lifetime prevalence of $70-80 \%$ in patients up to 20 years of age [10].

Understanding back pain in adolescents is crucial to obtain timely diagnosis and determine appropriate treatment. Proper treatment and management of LBP in the adolescent years can minimize back pain lasting into adulthood [11]. In the case of pediatric back pain due to spondylolysis and spondylolisthesis, a delay in diagnosis of 20 weeks measured between orthopedic surgeons versus other physicians was found to have severe consequences both physically and

Dino Samartzis

dsamartzis@msn.com

1 Department of Orthopaedic Surgery, RUSH University Medical Center, Orthopaedic Building, Suite 204-G, 1611W. Harrison Street, Chicago, IL 60612, USA

2 International Spine Research and Innovation Institute, RUSH University Medical Center, Chicago, USA psychologically [12]. If individuals develop LBP at a young age, they are more likely to suffer from recurrent/chronic LBP later on in life [13]. Such individuals become more sedentary, activity decreases, quality of life diminishes, and psychological distress may develop [14]. Furthermore, the time between symptom onset, accurate work-up, and effective treatment can be improved.

This rise in LBP incidence can be considered a public health issue as it creates a global burden of disease and carries up to 3.5 times risk for continuation of issues into adulthood [11]. Low back pain is the world's most disabling condition in adults [15-17]. Despite its high prevalence, $90 \%$ of the cases have no identifiable cause [16, 17]. While most people with LBP recover shortly after onset, approximately $44 \%$ of them experience recurrent LBP within 1 year and $10-25 \%$ of them develop chronic LBP that lasts for 3 months or more $[18,19]$.

The direct and indirect costs of LBP are enormous, currently noted as over 90 billion USD annually in the USA alone; however, such estimates have largely pertained to the adult population [20]. The cost of pediatric back pain is not limited to the direct health-care costs related to imaging, office visits, other diagnostic tests, and treatments. The burden also arises from missed work by parents and other associated expenses. Due to the higher risk of pain continuation that these pediatric patients carry into adulthood, these aforementioned costs may continue to accrue. These costs in the pediatric population have not been well established in the literature. This gap serves to emphasize the importance of studying pediatric LBP in hopes of gaining a better understanding of its etiology, proper work-up, effective treatment, and possible prevention on an international scale.

Currently, various etiologies have been hypothesized as being related to the rise of pediatric LBP. Some of the possible causes may be attributed to heavy or prolonged backpack use, lack of or appropriate physical activity, excessive video-game playing and/or television viewing, irregular sleep, biopsychosocial problems, and overweight/obesity $[9,14,21-23]$. In the USA alone, approximately $32 \%$ of children and adolescents are overweight or obese [24]. 
Obesity in children may lead to a cacophony of comorbidities, such as sleep apnea, metabolic and cardiovascular disorders, mental health and musculoskeletal issues [3]. In fact, $80 \%$ of children who are obese will continue to be obese in adulthood, carrying forth that risk profile for other comorbidities [3]. Lumbar disk degeneration, once thought to occur in adults, has also been noted in children with associated LBP and with or without sciatica [21]. In fact, overweight and obesity has been shown to have a threefold increased risk in the development of pediatric LBP [21]. With the rise of overweight and obesity worldwide along with the lack of physical activity and other risk factors, the incidence of spine-related changes and LBP will continue to rise in the young and may perhaps progress to more severe forms early-on in adulthood. In children with spine deformity, such as scoliosis, LBP may affect up to $30 \%$ of that population [25]. Furthermore, more than $60 \%$ of children reporting LBP also noted that their parents also suffered from LBP [14]. As such, it is essential to understand the history and risk factors of a child presenting with pain as well as the importance of the physical examination [10]. Furthermore, precise treatment algorithms for children with LBP are not well established and without general consensus. In addition, outcome tools to assess function, disability, and pain in the pediatric population are scarce and warrant further exploration. The outcomes of the pediatric population may be more variable compared to their adult counterparts, necessitating a more personalized or precision-based approach.

Although the study of LBP in adults has taken center stage over the years, understanding LBP in children is equally and perhaps more essential. In fact, in an age of big data and more precision-based approaches toward medical conditions [26], a greater emphasis on LBP in the young is imperative. If we broaden our understanding and knowledge of this condition, we can apply innovative technologies and omics (e.g., genomics, metabolomics) platforms to assess early disease development, determine risk factors, develop preventative measures, improve clinical management, develop novel targeted therapies, predict outcomes, and enhance the quality of life of children and their families. We should aim to educate the public and raise awareness of pediatric spine-related and pain issues. With globalization, an international consortium is needed to assess the impact of LBP across the population spectrum for children and adolescents, and help to develop robust guidelines for patient management and outcome assessment. As a spine community, we need to be much more proactive to thoroughly assess this potential substantial burden of disease in the young with the ultimate goal to have a healthier and productive society.

\section{Compliance with ethical standards}

Conflict of interest The authors have no financial or competing interests to disclose in relation to this work.

\section{References}

1. Shudy M, de Almeida ML, Ly S, Landon C, Groft S, Jenkins TL, Nicholson CE (2006) Impact of pediatric critical illness and injury on families: a systematic literature review. Pediatrics 118(Suppl 3):S203-S218

2. Rennick JE, Johnston CC, Lambert SD, Rashotte JM, Schmitz N, Earle RJ, Stevens BJ, Tewfik T, Wood-Dauphinee S (2011) Measuring psychological outcomes following pediatric intensive care unit hospitalization: psychometric analysis of the Children's Critical Illness Impact Scale. Pediatr Crit Care Med 12:635-642

3. O'Connor EA, Evans CV, Burda BU, Walsh ES, Eder M, Lozano $P$ (2017) Screening for obesity and intervention for weight management in children and adolescents: evidence report and systematic review for the US Preventive Services Task Force. JAMA 317:2427-2444

4. Watson RS, Choong K, Colville G, Crow S, Dervan LA, Hopkins RO, Knoester H, Pollack MM, Rennick J, Curley MAQ (2018) Life after critical illness in children-toward an understanding of pediatric post-intensive care syndrome. J Pediatr 198:16-24

5. Chu PY, Maslow GR, von Isenburg M, Chung RJ (2015) Systematic review of the impact of transition interventions for adolescents with chronic illness on transfer from pediatric to adult healthcare. J Pediatr Nurs 30:e19-e27

6. Taimela S, Kujala UM, Salminen JJ, Viljanen T (1997) The prevalence of low back pain among children and adolescents: a nationwide, cohort-based questionnaire survey in Finland. Spine (Phila $\mathrm{Pa}$ 1976) 22:1132-1136

7. Swain MS, Henschke N, Kamper SJ, Gobina I, Ottova-Jordan V, Maher CG (2014) An international survey of pain in adolescents. BMC Public Health 14:447

8. King S, Chambers CT, Huguet A, MacNevin RC, McGrath PJ, Parker L, MacDonald AJ (2011) The epidemiology of chronic pain in children and adolescents revisited: a systematic review. Pain 152:2729-2738

9. Balague F, Troussier B, Salminen JJ (1999) Non-specific low back pain in children and adolescents: risk factors. Eur Spine $\mathbf{J}$ 8:429-438

10. MacDonald J, Stuart E, Rodenberg R (2017) Musculoskeletal low back pain in school-aged children: a review. JAMA Pediatr 171:280-287

11. Chou R, Qaseem A, Snow V, Casey D, Cross JT Jr, Shekelle P, Owens DK, Clinical Efficacy Assessment Subcommittee of the American College of P, American College of P, American Pain Society Low Back Pain Guidelines P (2007) Diagnosis and treatment of low back pain: a joint clinical practice guideline from the American College of Physicians and the American Pain Society. Ann Intern Med 147:478-491

12. Nielsen E, Andras LM, Skaggs DL (2018) Diagnosis of spondylolysis and spondylolisthesis is delayed 6 months after seeing nonorthopedic providers. Deformity 6:263-266

13. Paranjape S, Ingole V (2018) Prevalence of back pain in secondary school students in an urban population: cross-sectional study. Cureus 10:e2983

14. Gunzburg R, Balagué F, Nordin M, Szpalski M, Duyck D, Bull D, Mélot C (1999) Low back pain in a population of school children. Eur Spine J 8:439-443 
15. GBD (2016) Disease and Injury Incidence and Prevalence Collaborators (2017) Global, regional, and national incidence, prevalence, and years lived with disability for 328 diseases and injuries for 195 countries, 1990-2016: a systematic analysis for the global burden of disease study 2016. Lancet 390:1211-1259

16. Wong AY, Karppinen J, Samartzis D (2017) Low back pain in older adults: risk factors, management options and future directions. Scoliosis Spinal Disord 12:14

17. Wong AY, Samartzis D (2016) Low back pain in older adultsthe need for specific outcome and psychometric tools. J Pain Res 9:989-991

18. Shen FH, Samartzis D, Andersson GB (2006) Nonsurgical management of acute and chronic low back pain. J Am Acad Orthop Surg 14:477-487

19. Andersson GBJ (1999) Epidemiological features of chronic lowback pain. Lancet 354:581-585

20. Dagenais S, Caro J, Haldeman S (2008) A systematic review of low back pain cost of illness studies in the United States and internationally. Spine J 8:8-20

21. Samartzis D, Karppinen J, Mok F, Fong DY, Luk KD, Cheung KM (2011) A population-based study of juvenile disc degeneration and its association with overweight and obesity, low back pain, and diminished functional status. J Bone Joint Surg Am 93:662-670

22. Negrini S, Carabalona R Backpacks on! schoolchildren's perceptions of load, associations with back pain and factors determining the load. Spine (Phila Pa 1976) 27:187-195

23. Szita J, Boja S, Szilagyi A, Somhegyi A, Varga PP, Lazary A (2018) Risk factors of non-specific spinal pain in childhood. Eur Spine J 27:1119-1126

24. Ogden CL, Carroll MD, Kit BK, Flegal KM (2014) Prevalence of childhood and adult obesity in the United States, 2011-2012. JAMA 311:806-814

25. Wong AYL, Samartzis D, Cheung PWH, Chung MTH, Cheung JP How common is back pain and what biopsychosocial factors are associated with back pain in patients with adolescent idiopathic scoliosis? Clin Orthop Rel Res (in press)

26. Samartzis D, Alini M, An HS, Karppinen J, Rajasekaran S, Vialle L, Wang JC, de Kleuver M (2018) Precision spine care: a new era of discovery, innovation, and global impact. Global Spine J $8: 321-322$ 